\title{
Exploring enablers of sexually transmitted infections among illegal gold miners in the midlands region of Zimbabwe
}

\author{
Mathew Nyashanu1, Rumbidzai Chireshe², Dung Ezekiel Jidong ${ }^{3}$, Wendy Nyashanu ${ }^{4}$, \\ Mandu Stephen Ekpenyong ${ }^{5}$
}

\begin{abstract}
${ }^{1}$ Department of Health and Allied Professions Nottingham Trent University, 50 Shakespeare Street, Nottingham, NG1 4FQ, United Kingdom

${ }^{2}$ Department of Nursing and Public Health KwaZulu Natal University, Durban, South Africa

${ }^{3}$ Department of Psychology, Nottingham Trent University Shakespeare street, Nottingham, United Kingdom

${ }^{4}$ Department of Community Health nursing Birmingham and Solihull Mental Health Trust United Kingdom

${ }^{5}$ Department of Nursing, Manchester Metropolitan University, Manchester United Kingdom
\end{abstract}

Received: 26 October 2020

Revised: 03 March 2021

Accepted: 04 March 2021

\section{*Correspondence:}

Dr. Mathew Nyashanu,

E-mail: mathew.nyashanu@ntu.ac.uk

Copyright: () the author(s), publisher and licensee Medip Academy. This is an open-access article distributed under the terms of the Creative Commons Attribution Non-Commercial License, which permits unrestricted non-commercial use, distribution, and reproduction in any medium, provided the original work is properly cited.

\begin{abstract}
Background: Sub-Saharan Africa faces by far the highest rate of HIV and other Sexually Transmitted Infections (STIs). Illegal mineworkers are considered at risk for HIV and sexually transmitted infections (STIs). Men are generally not receptive to health promotion messages.

Methods: This study explored the enablers of sexually transmitted infections. The study utilized a qualitative approach. A total of 40 participants were recruited. Semi structured interviews were used to collect data. A thematic approach was used to analyze the data. Zimbabwe, like any other country in the sub-Saharan region of Africa, has been affected by the epidemic of HIV/AIDS and other STIs, because of poor sexual health education.

Results: The study found that the enablers of STIs included poor sexual health knowledge, substance misuse, prolonged stay from family, stigma, lack of entertainment, cultural status, and poor sexual health services.

Conclusions: STIs among illegal gold miners is a public health concern that needs urgent attention in many developing countries.
\end{abstract}

Keywords: HIV, Illegal gold miners, STIs, Stigma, Sub-Sahara Africa

\section{INTRODUCTION}

Generally, mineworkers are considered a population at risk for HIV and sexually transmitted diseases, due to risk behaviours associated with migratory work patterns. SubSaharan Africa faces by far the highest rate of HIV and other sexually transmitted infections (STIs). Zimbabwe, like any other country in the sub-Saharan region of Africa, has been affected by the epidemic of HIV/AIDS and other STIs; because of poor sexual health education. ${ }^{1}$ Several contributing factors have been suggested to explain reasons for the high prevalence of STIs in mining districts, in the sub-Saharan regions of Africa. This includes factors such as cultural status, lack of male circumcision, migration, untreated sexually transmitted infections because of stigma and multiple sexual relationships. ${ }^{2}$ Men who stay away from their sexual partners due to migration from their hometowns to the mines are more likely to have additional sexual partners and are therefore more likely to be expose to HIV and STIs. ${ }^{3}$ STIs are a major global cause of acute illness, infertility, long-term disability and death with serious 
medical and psychological consequences of millions of men, women and infants. ${ }^{4}$

The World Health Organization (WHO) estimated that nearly 1 million people are infected every day. ${ }^{5}$ With 63 million cases in Africa and a global estimate of 357 million new cases annually of four curable sexually transmitted infections among people aged 15-49 years, Chlamydia trachomatis with 131 million, Neisseria gonorrhoeae with 78 million, syphilis with 6 million, and Trichomonas vaginalis with 142 million. The prevalence of some viral sexually transmitted infections is similarly high, with an estimated 417 million people infected with herpes simplex type 2, and approximately 291 million women harboring the human papillomavirus. The prevalence of these sexually transmitted infections varies by region and gender. ${ }^{6}$ These epidemics have a profound impact on the health and lives of children, adolescents, and adults worldwide. Syphilis in pregnancy leads to over 300000 fetal and neonatal deaths each year and places an additional 215000 infants at increased risk of early death. The human papillomavirus infection is responsible for an estimated 530000 cases of cervical cancer and 264000 cervical cancer deaths each year. Sexually transmitted infections, such as gonorrhea and chlamydia, are important causes of infertility worldwide. In some cases the presence of a sexually transmitted infection, such as syphilis, gonorrhea, or herpes simplex virus infection, greatly increases the risk of acquiring or transmitting HIV infection (by two to three times, in some populations), and in general the physical, psychological and social consequences of sexually transmitted infections severely compromise the quality of life of those infected. ${ }^{6}$

Illegal mining areas often do not provide accommodation for spouses or families, and most illegal mineworkers migrate alone. As a result, and because these miners earn higher incomes than the average male in the area, they may choose to have, and be able to support, their wives and girlfriends, or may interact with female sex workers in the areas surrounding the mines. ${ }^{7}$ Young people in subSaharan Africa face significant challenges accessing sexual and reproductive health information and services. These challenges are shaped in part by sociocultural factors, including stigma. The environment of pervasive stigma surrounding the sexual and reproductive health of unmarried young people manifest itself in multiple forms, ranging from verbal harassment and social isolation by community members, peers, and healthcare providers. Stigma is a barrier to people accessing sexual and reproductive health services and there is excessive questioning, scolding and requirements to bring sexual partners or parents to receive services at health facilities that will make patients shy away from accessing health care. $^{8}$

Many young adults, despite widespread prevention and education efforts, engage in behaviours that place them at risk of HIV infection. Certain risk factors such as lack of sexual health education, substance use, alcohol consumption and non-use of contraceptives have been identified as being associated with multiple sexual partnerships. ${ }^{9}$ There is a general conception that alcohol consumption increases the risk of multiple sex partners. A study of sexually active youths in Malawi found that, alcohol use increases the prevalence of multiple sex partners. ${ }^{10}$

Despite their high global incidence, STIs remain a neglected area of research ${ }^{5}$. Limited data on sexually transmitted infections, data disaggregated by sex, compromise the response the health providers could give to the people. There is inconsistent reporting between and within regions and countries. Resource development projects such mining have often been associated with increases in rates of STIs in communities. This has been attributed largely to the influx of mobile workforces of hundreds to thousands of temporary illegal mineworkers, often young, male, and single. These workers have gained the reputation, of engaging in risky sexual behaviors, that leads to increases in STIs.

Because STIs are strongly linked to social determinants, understanding community factors that affect the burden of these infections at the population level is critical. ${ }^{11}$ As communities may be impacted by the illegal mining, the population-level associations with STIs need to be understood to identify any increase in prevalence and enablers of sexually transmitted infection that may require intervention. Therefore, the objective of this study was to explore the enablers of sexually transmitted infections in Munyati to gain insight into the social and health impacts of illegal mining activity.

\section{METHODS}

\section{Study type}

This was a primary qualitative enquiry study.

\section{Study place}

Munyati is a small town situated in the midlands province of Zimbabwe. It is located 29 kilometres north of Kwekwe on the main Harare-Bulawayo road. In 1938 a power station was built in the area and a village was established to house the personnel. The surrounding area has large deposits of gold, copper, stibnite and tungsten. In the run up to the new millennium Zimbabwe experienced one of its worst economic problem leading to an influx of illegal gold miners in Munyati.

\section{Research design}

The study utilized a qualitative enquiry approach. A thematic analysis framework was used to analyze data exploring the enablers of sexual transmitted infections among illegal gold miners in Zimbabwe. Thematic analysis involves an interpretive procedure, in which data is methodically organized and examined to project 
patterns within the data and offer a revealing account of the phenomenon 12. This method is ideal for forming meaningful themes with no intention to create theory 13. The approach is normally used to generate rich data and comprehensive conception of complex phenomenon 14 . All the authors independently read data many times to extract and code any themes related to the aim of this study.

\section{Research recruitment procedure}

The study utilized a convenience sampling method to recruit the research participants. A total of 40 illegal gold miners were recruited to take part in the study. The research participants were recruited between May to July 2020. The researchers wrote letters to managers of informal organizations of small-scale gold miners asking for permission to recruit their members. Only those members who agreed to take part in the study had their details passed on to the researchers to organize the interviews. All the research participants were given an information sheet and consent form and had the opportunity to ask questions about the study. Prior to the interviews all research participants signed a consent form which allowed them to leave the research study without giving any reason. Advertisements to recruit participants were shared on different social networking sites. The inclusion criteria were that the research participant should have been mining gold in the past five years. The threshold of five years was meant to give the research participants a standard experience and length of stay. Initially, fifty participants were recruited as part of the study. However, five of them dropped due to personal reasons. The final sample consisted of forty-five participants. After interviewing forty participants a saturation point was reached when no more new data was being generated and the interviews were stopped. Confidentiality and anonymity were assured for the research participants. The rapport building sessions comprised of sharing purposes and signing of consent forms of the study with participants before interviews. The research was contacted between May 2020 and August 2020.

\section{Interview schedule}

The interview schedule was designed by reading through the past literature related to sexual health risky groups and discussion among the researchers about qualitative research. The schedule was made up of semi-structured questions and probs. The schedule was piloted with four illegal gold miners who did not take part in the study. Their recommendations and feedback were used to improve the interview schedule. All the interviews were contacted in English.

\section{Data collection}

The interviewees were contacted through an online telephone platform WhatsApp (video). The method was preferred in line with the COVID-19 lock down and social distancing. Each interview lasted for one hour. The research participants were provided with vouchers for mobile data bundles to enable their WhatsApp to work. The bundles were delivered to the research participants through the managers of the informal groups who brought the illegal gold miners together.

\section{Ethical consideration}

The study was conducted in line with the Ethical Standards of the 1964 Helsinki Declaration and its Later Amendments or Comparable Ethical Standards. Informed consent was obtained from all research participants. Additionally, formal approval was given by the Joint Research Council of Zimbabwe (JREC).

\section{Data analysis}

Following recording interviews, the data was transcribed verbatim and analyzed thematically. According to 14 recommended different methods of transcription based on the analytical methods. The study used orthographic transcription which consisted of a "verbatim" account of all verbal as well as non-verbal expressions. Nonverbal responses were also recorded and factored in during the data analysis. Analysis was done by all the authors. The transcripts were read many times condensed and obtained meaningful statement. Themes and subthemes were devised. The authors discussed and reached consensus on the final themes that were identified as the final findings of the research study.

\section{RESULTS}

Table 1: Demographic information for research participants.

\begin{tabular}{|ll|}
\hline Number of participants & $\mathbf{4 0}$ \\
\hline Sex & All male \\
\hline Age range & $18-36$ years \\
\hline Married & 20 \\
\hline Single & 20 \\
\hline
\end{tabular}

Following data analysis, the study found that the enablers of sexual transmitted infections among illegal gold miners were poor sexual health knowledge/resistance to condom use, substance misuse, prolonged stay away from family, stigma, lack of entertainment, cultural status and poor sexual health services.

\section{Poor sexual health knowledge/resistance to condom use}

The research participants reported poor sexual health knowledge including resistance to condom use. They indicated shared sentiments against condom use in general. "It depends with your body and blood, there are so many people who have sex with different partners but they have never had any infection... You can just be 
unlucky and you can end up infected with HIV or a sexual transmitted infection" A 44 year old man

"Honestly, I have no time for condoms. It is like eating a sweet while covered in plastic .... Honestly, there is no test we all know that..." A 28-year-old man

\section{Substance misuse}

Alcohol misuse and drugs like marijuana was blamed for having unprotected sex.

"I always carry condoms in my pocket but once I take alcohol or marijuana, I become so high that I forget using a condom or having protected sex....... It only comes back to me early in the morning that I should have used a condom" A 25-year-old man

"When I am sober I always know the dangers of having multiple sex partners without protection but once I smoke some chamba/weed all those thoughts fly out of my mind and end up in unprotected sex... Truly speaking alcohol and weed are the source of reckless sexual health behaviour" A 29 year old man

\section{Prolonged stay away from family}

The research participants reported prolonged periods of staying away from home ending up in extra marital relationship and sometimes catching sexual transmitted infections.

" You know this work of gold panning takes me away from home for a long period sometimes close to five months without a wife..... As a man I can't go for five months without seeing a woman...I will have no option but to find a sex commercial worker" A 29 year old man

"Honestly, how can I stay more than three months without a woman....I can't go back home because its expensive I will end up getting one of the women who come to sell sex here" A 34 year old man.

\section{Lack of entertainment}

The research participants reported lack of entertainment as the reason why they spent most of their time drinking alcohol with sex commercial workers who come to the remote areas to sell sex.

"After work there is nothing to do except drinking the local brew and have fun with sex commercial worker... Honestly, that's the entertainment everyday" A 30-yearold man

"There is nothing do here, when I finish work I have to smoke weed and have fun with women who live around here...... I can't go and sleep in my small house alone" A 32 year old man

\section{Stigma}

Stigma was reported as one of the issues that deter them to access treatment leading to continuous spreading of the infection, only to present late at treatment centers when the situation become serious.

"The problem is going to the clinic when I am infected with sexual transmitted infections......The nurse will just embarrass me............. Sometimes they ask me to bring the woman I slept with...honestly that's embarrassing I would rather seek traditional herbs than to go to the clinic" A 28-year-old man.

"The last time I went to the clinic with a sexual transmitted infection I could see the nurses' laughing at me and I just said to myself this is the last time I will come here...Another nurse told me to bring my wife it was really embarrassing" A 27 year old man

\section{Cultural status}

The participants reported that high status was associated with having multiple partners and many people were competing to outdoor each other.

"I always make sure that I approach every new woman who comes here before anyone could take them......People always view me with high status because I have more than three women here" A 40-yearold man

"Some people are not good once they are lucky to get gold they literally take all the women here leaving us with nothing just because they can afford to give them money......No wonder why many people are affected by sexual transmitted infections here" A 33 year old man

\section{Poor sexual health services}

The research participants reported that the sexual health clinic was located 35 kilometers away and it was difficult to get transport or walk resulting in many people delaying treatment and spreading the infection within the mining area.

"The sexual health clinic is 35 kilometers away and there is no transport........ I sometimes rely on traditional medicine until I get transport to go to the clinic for treatment". A 36-year-old man

"The problem here many people stay long periods without treatment because there is no clinic anywhere near.....they will only get treated when they get transport and during the meantime people will be spreading the infections to each other really need a clinic here".

A 39-year-old man. 


\section{DISCUSSION}

Poor sexual health knowledge and resistance to condom use can exacerbate the spread of sexual transmitted infections including HIV. ${ }^{15}$ More so, this can be worse in rural remote set ups characterised by poor socioeconomic outlook and weak sexual health infrastructure. In this study, the research participants reported poor sexual health knowledge including resistance to condom use. They indicated shared sentiments against condom use in general. Resistance to condom use is not a new phenomenon in many communities and is normally supported by poor sexual health knowledge. ${ }^{16}$ There is need for the central government to raise sexual health awareness among rural communalities as an initiative to prevent the spread of sexual transmitted infections. In doing so there is need to explain the importance of condom use to increase its uptake and prevent the spread of sexual transmitted infections in these remote communities. More importantly, the use of radios and social media like WhatsApp in raising sexual health awareness and condom use can be effective in reaching out to such communities living in remote parts of the country.

Substance misuse can impair judgement and induce impulsive responses to issues associated with sexual health behaviours. ${ }^{16}$ This can be prevalent in communities living in remote areas where there are not any other recreational activities. There is a very strong association between substance misuse and high prevalence of sexual health transmitted infections. ${ }^{17}$ The research participants reported alcohol misuse and drugs like marijuana for having unprotected sex. This was also exacerbated by poor recreational activities in the remote location. There is need for the central government to officially recognize these illegal gold miners and provide recreational settings like gyms, parks, and other amenities to increase engagement and prevent substance misuse. There is also need for the ministry of health through the sexual health promotion service to raise awareness on the impact of substance misuse in these communities through commonly available mediums like radios and WhatsApp. More importantly, there is need for the central government to have clear policies and strategies that support communities to desist from using drugs using community-based methods.

Evidence shows that there is an association between working away from the family and engaging in extramarital affairs especially among lowly paid men living away from home. ${ }^{18}$ There is evidence of high prevalence of HIV and STIs among migrant workers who left their families home. In most cases, migrant illegal miners largely represent a group of sexually active men who are separated from their regular partners for extended periods. ${ }^{19}$ The research participants reported prolonged periods of staying away from home ending up in extra marital relationship and sometimes catching sexual transmitted infections. Research has noted that the migrant nature of work is characterised by access to commercial sex work, high alcohol use and low condom use. ${ }^{20,21}$ The sociocultural and structural conditions that are fostered by these illegal mining communities appear to exacerbate sexual health inequalities and sexually transmitted infections among the people who live and work in these mining communities. There is need for STIs prevention and testing service delivery models that incorporate STIs and HIV testing and treatment outreach in hard to reach areas including illegal gold mining outposts. It is also important that local, national, and global STIs and HIV control efforts should consider the realities and needs of similar subpopulations.

In most informal and illegal businesses there is lack of structured health systems and amenities to cater for the population around. ${ }^{22}$ Such settings are associated with lack of structured health services, lack of places for entertainment for example grounds for social community games and activities to keep the population engaged while away from work. ${ }^{23}$ The research participants reported lack of entertainment and spending most of the time drinking alcohol with sex commercial workers who come to the remote areas to sell sex. There is need for the central government through the ministry of industry and commerce to formalize these illegal gold mines and pave way for the formalization of the health systems in the areas in question. Again, as alluded to earlier on once these illegal mines are formalized Activities that positively engage communities like green spaces and gyms can be erected to engage communities and prevent them from engaging in risk sexual behaviour.

Stigma is one of the issues that can deter people from seeking treatment and continue to spread the infection 24. Stigma involves negative attitudes or discrimination against someone based on a distinguishing characteristic such as a mental illness, health condition or undesirable characteristics. ${ }^{25}$ In this study, the research participants reported stigma as one of the issues that deterred them from accessing treatment leading to continuous spread of the infection, only to present late at treatment centers when the situation become serious or dire. There is need for the central government through the ministry of health to come up with protracted strategies in reducing stigma and increase the uptake of STIs treatment among vulnerable and sometimes risk social groups like illegal gold miners. More importantly, there is need for outreach sexual health awareness and treatment covering remote areas including illegal gold mining remote areas.

In some communities, having multiple partners is regarded as high status among men. ${ }^{26}$ Such cultural norms encourage individuals to normalize multiple sexual partners sometimes with very little or no knowledge of the consequences. The status that goes with having multiple partners is usually common among vulnerable social groups like illegal gold miners. ${ }^{27}$ The research participants reported that there is high status associated with having multiple partners and many people were 
competing to outdo each other thereby spreading STIs. This again is a depiction of a practice that makes the illegal gold mining community vulnerable to STIs. There is need to raise awareness on the impact of risk behaviour as part of $\mathrm{c}$ preventing STIs among vulnerable communities. More importantly the central government need to establish and strengthen health systems in hardto-reach communities like illegal gold miners.

Most areas where illegal mining activities take place are characterised by poor health systems due to location and designated purposes of the land. ${ }^{28}$ Many people who come to undertake illegal gold mining in these areas struggle to get treatment due to non-availability of health facilities. Coupled with these difficulties are poor roads and transport linking such areas to viable health services across the country. ${ }^{29}$ The research participants reported that the sexual health clinic was located 35 kilometers away and it was difficult to get transport or walk resulting in many people delaying treatment and spreading the infection within the mining area. There is need for the central government through the ministry of health to establish mobile clinics which can be used to service such remote areas. The mobile clinics also need to be supported by health promotion services to raise awareness on issues around sexual health to increase uptake of STIs treatment.

\section{Implication for sexual health professionals}

Sexual health professionals working in developing countries like Zimbabwe need to look far beyond the regularly serviced areas to include locations where vulnerable populations live and work. There is need for sexual health professionals to work with other professionals in raising sexual health awareness and increase uptake of STIs treatment.

Limitations: Meanwhile, there are so many provinces with illegal gold miners in Zimbabwe, this study was conducted in just one province. In future there is need to conduct such a study in a number of provinces to enable comparison and understanding the pattern of sexual transmitted infections among illegal gold miners in the country.

This study utilised a qualitative approach, in future a research utilising both qualitative and quantitative research approaches might be ideal to enhance the understanding and analysis of issues from a variety of background.

\section{CONCLUSION}

STIs among illegal gold miners is a public health concern that needs urgent attention in many developing countries. There is need to provide sexual health services beyond the regular residential areas to include informal and hard to reach areas located in remote parts of the country.

\section{ACKNOWLEDGMENTS}

Authors sincere thanks go to all men who took part in this research study.

\section{Funding: No funding sources \\ Conflict of interest: None declared \\ Ethical approval: The study was approved by the Institutional Ethics Committee}

\section{REFERENCES}

1. Kalichman SC, Ntseane D, Nthomang K, Segwabe M, Phorano O, Simbayi LC. Recent multiple sexual partners and HIV transmission risks among people living with HIV/AIDS in Botswana. Sexually transmitted infections. 2007;83(5):371-5.

2. Chialepeh WN, Susuman AS. Risk factors of inconsistent condom use among sexually active youths: Implications for human immunodeficiency virus and sexual risk behaviours in Malawi. Journal of Asian and African Studies. 2017;52(4):484-96.

3. Baltazar CS, Horth R, Inguane C, Sathane I, César F, Ricardo $\mathrm{H}$, et al. HIV prevalence and risk behaviors among Mozambicans working in South African mines. AIDS and Behavior. 2015;19(1):59-67.

4. World Health Organization. Global incidence and prevalence of selected curable sexually transmitted infections-2008. World Health Organization; 2012.

5. Unemo M, Bradshaw CS, Hocking JS, de Vries HJ, Francis SC, Mabey D, et al. Sexually transmitted infections: challenges ahead. The Lancet infectious diseases. 2017;17(8):e235-79.

6. World Health Organization. Global health sector strategy on sexually transmitted infections 20162021: toward ending STIs. World Health Organization; 2016.

7. Corno L, De Walque D. Mines, migration and HIV/AIDS in Southern Africa. Journal of African Economies. 2012;21(3):465-98.

8. Nyblade L, Stockton M, Nyato D, Wamoyi J. Perceived, anticipated and experienced stigma: exploring manifestations and implications for young people's sexual and reproductive health and access to care in North-Western Tanzania. Culture, health \& sexuality. 2017;19(10):1092-107.

9. Morris M, Vu L, Leslie-Cook A, Akom E, Stephen A, Sherard D. Comparing estimates of multiple and concurrent partnerships across population based surveys: implications for combination HIV prevention. AIDS and Behavior. 2014;18(4):783-90.

10. Coma JC. When the group encourages extramarital sex: Difficulties in HIV/AIDS prevention in rural Malawi. Demographic Research. 2013;28:849-80.

11. Hogben M, Leichliter JS. Social determinants and sexually transmitted disease disparities. Sexually transmitted diseases. 2008;35(12):S13-8.

12. Smith J, Firth J. Qualitative data analysis: the framework approach. Nurse researcher. $2011 ; 18(2): 52-62$. 
13. Tesch R. Qualitative research: Analysis types and software. Routledge; 2013.

14. Braun V, Clarke V. Using thematic analysis in psychology. Qualitative research in Psychol. 2006;3(2):77-101.

15. Sherrard J, Wilson J, Donders G, Mendling W, Jensen JS. 2018 European (IUSTI/WHO) International Union against sexually transmitted infections (IUSTI) World Health Organisation (WHO) guideline on the management of vaginal discharge. International journal of STD \& AIDS. 2018;29(13):1258-72.

16. Holt M, Newman CE, Lancaster K, Smith AK, Hughes S, Truong HH. HIV pre-exposure prophylaxis and the 'problems' of reduced condom use and sexually transmitted infections in Australia: a critical analysis from an evidence-making intervention perspective. Sociology of health \& illness. 2019;41(8):1535-48.

17. Traeger MW, Cornelisse VJ, Asselin J, Price B, Roth NJ, Willcox J, et al. Association of HIV preexposure prophylaxis with incidence of sexually transmitted infections among individuals at high risk of HIV infection. Jama. 2019;321(14):1380-90.

18. Stuckler D, Steele S, Lurie M, Basu S. Introduction: 'Dying for gold': The effects of mineral miningon HIV, tuberculosis, silicosis, and occupational diseases in southern Africa. International Journal of Health Services. 2013;43(4):639-49.

19. Wang Y, Lu R, Wu G, Lan R, Ou R, Zhang Y, et al. Changing trends of HIV, syphilis, and hepatitis C among male migrant workers in Chongqing, China: Nine consecutive cross-sectional surveys, 2010 2018. International J Environmental research Public health. 2020;17(3):875.

20. Semá Baltazar C, DeLima YV, Ricardo H, Botão C, Chitsondzo Langa D, da Costa $\mathrm{P}$, et al. HIV prevalence and TB in migrant miners communities of origin in Gaza Province, Mozambique: The need for increasing awareness and knowledge. Plos one. 2020;15(4):e0231303.

21. Nicholas PK, Mfono N, Corless IB, Davis SM, O'Brien E, Padua J, et al. HIV vulnerability in migrant populations in southern Africa: Sociological, cultural, health-related, and human-rights perspectives. International J Africa Nursing Sci. 2016;5:1-8.

22. Mutisya E, Yarime M. Understanding the grassroots dynamics of slums in Nairobi: the dilemma of Kibera informal settlements. Int Trans J Eng Manag Appl Sci Technol. 2011;2(2):197-213.

23. Yakovleva N. Perspectives on female participation in artisanal and small-scale mining: A case study of Birim North District of Ghana. Resources Policy. 2007;32(1-2):29-41.

24. Geter A, Herron AR, Sutton MY. HIV-related stigma by healthcare providers in the United States: A systematic review. AIDS patient care and STDs. 2018;32(10):418-24.

25. White TS. The whitewashing of wilderness: how history and symbolic annihilation influence black Americans' participation at national parks; 2018.

26. Hunter M. Masculinities, multiple-sexual-partners, and AIDS: the making and unmaking of Isoka in KwaZulu-Natal. Transformation: critical perspectives on Southern Africa. 2004;54(1):123-53.

27. Wilches-Gutierrez J, Documet P. What is known about sexual and reproductive health in Latin American and Caribbean mining contexts? A systematic scoping review. Public health reviews. 2018;39(1):1-3.

28. Hilson G, Banchirigah SM. Are alternative livelihood projects alleviating poverty in mining communities? Experiences from Ghana. The Journal of Development Studies. 2009;45(2):172-96.

29. Hinton JJ, Veiga MM, Veiga AT. Clean artisanal gold mining: a utopian approach?. J Cleaner production. 2003;11(2):99-115.

Cite this article as: Nyashanu M, Chireshe R, Jidong DE, Nyashanu W, Ekpenyong MS. Exploring enablers of sexually transmitted infections among illegal gold miners in the midlands region of Zimbabwe. Int J Reprod Contracept Obstet Gynecol 2021;10:1321-7. 